DOI 10.37882/2500-3682.2021.11.01

\title{
ВОЗДЕЙСТВИЕ УРОВНЯ ФОРМИРОВАНИЯ ПЕДАГОГИЧЕСКОЙ НАБЛЮДАТЕЛЬНОСТИ НА ВЗАИМОДЕЙСТВИЕ С ОБУЧАЮЩИМИСЯ
}

\section{THE IMPACT OF THE LEVEL OF FORMATION OF PEDAGOGICAL OBSERVATION ON INTERACTION WITH STUDENTS}

\section{U. Gadzhieva}

Summary: This article is devoted to the actual problem of the formation of pedagogical observation, the level of which directly affects the various forms and types of interaction between a teacher and students in the process of teaching activities. The education system at the present stage is undergoing various changes, which in turn impose new requirements on the personality of the teacher. These requirements are based on the high professionalism of the teacher, who must have various systemforming qualities and properties. One of these properties is pedagogical observation, which is one of the most important components of communicative skills. With the help of these communicative skills, social competence and attention to the opinions of other people are ensured, the ability to listen and start a dialogue, take part in the general analysis of emerging difficulties, unite in groups and establish joint effective interaction and partnership between adults and children.

Keywords: pedagogical observation, communication, social competence, interaction, perception, behavior, mental processes, psychophysical states.

\section{Введение}

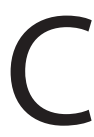

овременный этап развития общества предъявляет высокие требования к системе образования, которая подвергается различным изменениям. И данные изменения затронули саму модель культурноисторического развития. Но каким бы изменениям не подвергалась система образования главный акцент делается на личности педагога, его профессионализме.

Все основные нововведения системы образования так или иначе связаны с деятельностью педагога. Успешное применение на практике разных инноваций связано с наличием у педагога высокого уровня профессиональных свойств. Именно таким системным свойством и является наблюдательность (В.С. Агеев, Б.Г. Ананьев, А.А. Бодалев, Л.С. Выготский, Н.В. Кузьмина, А.Н. Панкратов, А.М. Позднякова, Л.А. Регуш, и др.).

Современная психология, основываясь на мнении

\author{
Гаджиева Ума Басировна \\ К.n.н., доцент, Дагестанский государственный \\ университет \\ umkagb2@mail.ru
}

Аннотация: Данная статья посвящена актуальной проблеме формирования педагогической наблюдательности, уровень которой напрямую оказывает влияние на различные формы и виды взаимодействия педагога с учениками в процессе урочной деятельности. Система образования на современном этапе подвергается различным изменениям, которые в свою очередь предъявляют новые требования к личности педагога. Эти требования основываются на высоком профессионализме педагога, который должен обладать различными системообразующими качествами и свойствами. Одним из таких свойств и является педагогическая наблюдательность, которая является одним из важнейших компонентов коммуникативных умений. С помощью данных коммуникативных умений обеспечивается социальная компетентность и внимание к мнению других людей, способность выслушивать и начинать диалог, принимать участие в общем анализе возникающих трудностей, объединяться в группы и налаживать совместное эффективное взаимодействие и партнерство взрослых и детей.

Ключевые слова: педагогическая наблюдательность, коммуникация, социальная компетентность, взаимодействие, восприятие, поведение, психические процессы, психофизические состояния.

некоторых ученых, рассматривает наблюдательность важнейшим компонентом коммуникативных умений. Именно благодаря коммуникативным умениям обеспечивается социальная компетентность и внимание к мнению других людей, способность выслушивать и начинать диалог, принимать участие в общем анализе возникающих трудностей, объединяться в группы и налаживать совместное эффективное взаимодействие и партнерство взрослых и детей. Наблюдательность, по мнению многих авторов, напрямую влияет на отчетливость восприятия внешнего состояния разных людей [4, с. 78]. В.Н. Воронин считал, что благодаря наблюдательности обеспечивается четкость определения особенностей человека при социальном взаимодействии. По мнению А.А. Бодалева наблюдательность отвечает за ясность и дифференциацию социального восприятия [2, с. 52].

Обладая таким важным качеством как наблюдательность педагог получает возможность не только выявить происходящие изменения с учениками, но и оказать по- 
сильную помощь в преодолении затруднений, которые у детей возникают, скорректировать их действия и поведение.

Актуальность данной тематики связана с тем, что наблюдательность педагога как профессиональное свойство способствует умению подмечать и разглядеть неприметные, но характерные особенности психических состояний и процессов, внешние формы поведения. Благодаря педагогической наблюдательности педагог получает возможность правильно интерпретировать поведение обучающихся, спрогнозировать разнообразные психические процессы, предвидеть результаты работы самих педагогов, возникающие трудности в восприятии и понимании обучающимися учебной информации.

Взаимодействие в образовательном процессе нами рассматривается как взаимное влияние учителя на обучающихся и самих обучающихся на учителя, которое предполагает соответствующее отображение педагогом личности самого обучаемого, способность разглядеть и распознать особенности психических состояний обучающихся в различные ситуативные моменты. И здесь важно уметь встать на их субъективную точку зрения, разглядеть и выявить определенные трудности в процессе усвоения и понимания обучающимися образовательной информации, уметь спрогнозировать более далекие результаты необходимого контакта с обучающимися. Все формы взаимодействия педагогов с обучающимися требуют от последних высокого профессионализма, гибкости и своевременного учета индивидуальных особенностей детей, которые в силу возраста не обладают сформированной познавательной и сенсорной сферой [3, с. 35].

Эти перечисленные формы взаимодействий педагога и обучающихся в самом образовательном процессе тесно переплетены с явлениями педагогической наблюдательности [6, с. 12].

Нами было проведено исследование основной целью которого было выявление воздействия уровня формирования педагогической наблюдательности на взаимодействие педагога с обучающимися в процессе урочной деятельности.

Для этого нами была создана программа наблюдений за взаимодействием педагога и обучающихся на самих уроках. Данная программа включала в себя именно те формы взаимодействия педагога с обучающимися на уроках, которые связаны с различными проявлениями элементов педагогической наблюдательности: перцептивный, эмпативный, понятивный, прогностический и Т.Д.

Созданная исследовательская программа включает в себя восемь критериев взаимодействия педагога с обучающимися в процессе уроков. Все они были объединены в четыре группы по уровню проявления перцептивности, эмпативности, понятийности, прогностичности и т.д.

Карта наблюдений включала в себя характерные стороны взаимодействия педагога и обучающихся, которые были связаны с такими проявлениями как:

- Перцептивный компонент: а. замечает ли и рассматривает ли педагог деформации в психологических состояниях обучающихся в процессе уроков?

б. замечает ли педагог деформации в поведенческих актах обучающихся?

- Понятийный компонент:

а. различает ли педагог деформации в вербальных особенностях поведения обучающихся?

б. выявляет ли педагог трудности обучающихся в осмыслении и логическом понимании образовательной информации?

- Эмпатийный компонент:

а. может ли педагог поставить себя на место обучающихся, понимает ли их психофизические особенности?

б. соответствуют ли оценочные суждения и требования педагога?

- Прогностический компонент:

а. прогнозирует ли педагог возможные осложнения в процессе усвоения обучающимися более трудного материала?

б. различает ли педагог далекие по времени итоги результатов собственного общения с обучающимися в процессе урочной деятельности?

Исходя из ситуации, что наблюдение должно иметь свои рамки и не позволяет распознать то, находится за пределами урочной деятельности или погрузиться достаточно далеко в задумки педагога, нами предполагалась беседа, с помощью которой мы могли получить ответы на те вопросы, которые нас интересовали.

Опросник состоял из следующих вопросов:

1. Обращаете ли Вы внимание на внешность обучающихся?

2. Можете ли Вы постоянно обращать ваше внимание на выражение лица, характерные жесты, походку и позу обучающихся?

3. Замечаете ли Вы определенные особенности речевой деятельности обучающихся?

4. Всегда ли Вы можете понять настроение и психофизические состояния обучающихся?

5. Можете ли Вы осуществлять детальный анализ поведения обучающихся в соответствии с той или иной ситуацией?

6. Смогли бы Вы избежать конфликтных ситуаций? 
7. Смогли бы Вы найти индивидуальный подход ко всем обучающимся в процессе собственного контакта с ними?

8. Смогли бы Вы поставить себя на место обучающихся?

9. Смогли бы Вы увидеть и распознать определенные затруднения, которые испытывают некоторые обучающиеся в понимании и осмыслении учебного материала?

10. Смогли бы Вы быстро скорректировать необходимый учебный и образовательный материал к особенностям его усвоения обучающимися, перестроиться в случае необходимости?

11. Можете ли Вы предвидеть далекие по времени последствия результатов собственного контакта с обучающимися в процессе урочной деятельности?

Проведенное исследование охватило 4 школы города Махачкалы: №33, №3, №4,7. В работе были задействованы 12 учителей данных школ, за каждым из которых было проведено 5 наблюдений. Наблюдением охватывалось старшее звено обучающихся.

\section{Выво $\Delta$}

В результате проведенного исследования за наблюдением всех исследуемых сторон взаимодействий учителей и учеников в процессе урочной деятельности нами были получены следующие выводы: учителя, характеризующиеся высоким уровнем формирования наблюдательности в 3 раза лучше, чем педагоги с низким уровнем формирования наблюдательности воспринимают и осмысливают различные психические состояния, подмечают деформации в коммуникативных характеристиках их поведенческих актов. Данные педагоги более отчетливо подмечают возникшие проблемы обучающих- ся в восприятии и усвоении необходимой информации, в 4 раза быстрее находят измененность поведения обучающихся, могут поставить себя на место учеников и осмыслить психические состояния детей.

Педагоги с высоким уровнем формирования наблюдательности в 6 раз чаще прогнозируют возникающие затруднения у обучающихся в процессе восприятия и усвоения ими учебной информации, а также предвидят результаты непосредственной коммуникации с обучающимися в процессе урочной деятельности.

Учителя, характеризующиеся высоким уровнем сформированности профессиональной наблюдательности в 5 раз чаще, чем преподаватели с низким уровнем сформированности профессиональной наблюдательности выдают более соответствующие оценочные высказывания и условия в отношении обучающихся.

Анализ выполненной работы показал возможность установления необходимого воздействия уровня формирования наблюдательности на целесообразность взаимодействия педагога и обучающихся в процессе урочной деятельности. Высокий уровень формирования наблюдательности помогает педагогу очень тонко ощущать изменения в педагогических ситуациях и скорректировать на основе этого направленность педагогических воздействий на обучаемых. Благодаря этому обеспечивается успешное и эффективное протекание учебно-образовательного и воспитательного процесса.

Учитывая итоги выполненной работы по всем внешне наблюдаемым проявлениям взаимодействий педагога с обучающимися, мы определенно выявили направленность воздействия уровня формирования педагогической наблюдательности учителя на все критерии взаимодействий педагога и обучающихся в процессе урочной деятельности.

\section{ЛИТЕРАТУРА}

1. Ананьев Б.Г. Избранные психологические труды в 2-х т.: - М.: Педагогика, 1980. - 288 с.

2. Бодалев А.А. Восприятие и понимание человека человеком. М., Изд-во МГУ, 1988. - 199 с.

3. Выготский Л.С. Проблема возраста // Собр.соч. в 6-ти т. 2. - М., 1984. - 268 с.

4. Попов С.В. Визуальное наблюдение. - Спб.: Речь, Семантика, 2002. - 320 с.

5. Панкратов А.Н., Панкратов В.Н. Психология управления людьми: практическое руководство. - М.: ИНТ психотерапии, 2004. - 73 с.

6. Регуш Л.А. Практикум по соблюдению и наблюдательности. - Спб.: Питер, 2003. - 174 с. 